\title{
APPLiCATION OF E-ProcesSES IN TOURISM MARKETING
}

\author{
Berislav Andrlic, Marko Sostar \& Mario Banozic
}
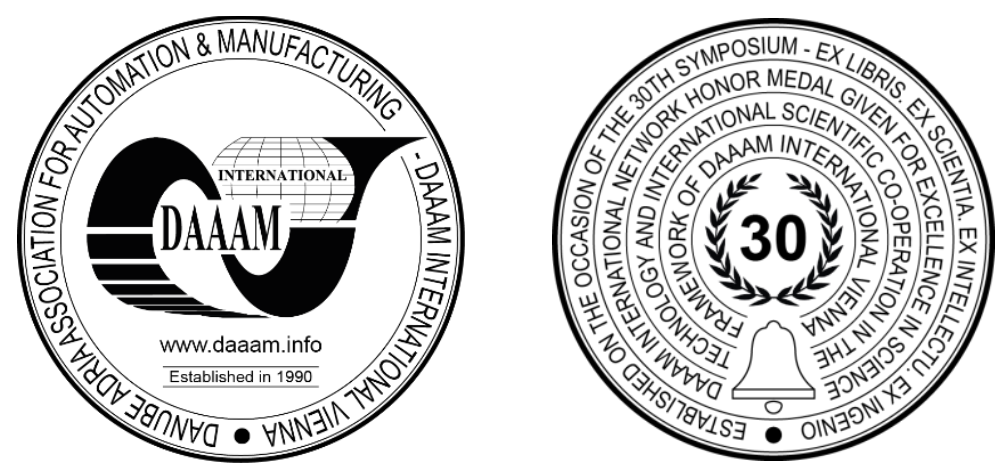

This Publication has to be referred as: Andrlic, B[erislav]; Sostar, M[arko] \& Banozic, M[ario] (2020). Application of E-Processes in Tourism Marketing, Proceedings of the 31st DAAAM International Symposium, pp.0004-0008, B. Katalinic (Ed.), Published by DAAAM International, ISBN 978-3-902734-29-7, ISSN 1726-9679, Vienna, Austria DOI: $10.2507 / 31$ st.daaam.proceedings.001

\begin{abstract}
Continuous research and monitoring of these factors is important, because they are important for the formation of marketing techniques. Changing economic conditions, new aspects of consumer behaviour and especially new technologies are likely to cause the emergence of new or growth of existing tourism markets. In developed economies, increasing attention is paid to the study of the role of new technologies in the field of tourism and hospitality. New processes in tourism and hospitality are aimed at the virtualization of tourism and hospitality products, because they cannot be digitized. In addition to the mentioned function, business processes supported by technology increase the efficiency of internal business entities in the market. This approach needs to be considered and implemented at the level of management, so this area is theoretically and practically explored in the paper.
\end{abstract}

Keywords: e-marketing; management; hospitality; processes

\section{Introduction}

The development of modern telecommunications and digital technology, and consequently the Internet, provide marketers with many new competitive opportunities. Simply put, traditional marketing activities are gaining echaracteristics, but we can also talk about a new, specific type - e-marketing in tourism. Talking from larger context, the Internet, as one of the most important technological phenomena of today, provides tourism entities with some completely new competitive opportunities, of which the most important is certainly the ability to provide immediate and always open access to information around the world.

The definition and analysis of the e-process leads us into a broad field of problematics, giving us an insight into the development of organizational structure, organizational resources and organizational culture, using new concept and an innovative vision and strategy. [12]

The development of technique and technology, as well as marketing in tourism and hospitality, requires the study and application of new modern concepts and approaches to the organization. Regardless of the size of the hotel, some modern business processes are applied, new achievements are used, especially the following: Business Process Management (BPM) and Customer Relationship Management (CRM), which is the focus of this paper. For solving research problem, desk research and interview with experts was used from June to August 2020. 


\section{Business Process Management in Tourism Industry}

Business Process Management (BPM) is a method by which a hotel adapts business processes to its business strategy, which leads to the optimization of their overall business by improving specific business activities within individual departments, throughout the hotel or between corporations. BPM can establish a model of automation, management and optimization of business processes throughout the hotel. It allows you to initiate minor changes, in just one or a few business processes, as well as expand optimization in a way that suits the organization. Some of the principles on which this approach is based are the following [1]:

- Orientation towards guests - Output to the process consumer and the price he realizes enables a measurement scale for process structuring.

- Cross-functional approach - A process, not an organizational unit, is an object of process management, which is in contrast to line management.

- Teamwork - Process thinking means team thinking because the basis of the process approach - integration across functional boundaries, can only be achieved through cooperation.

- Continuous improvement - Processes are not static structures but constant subjects of new changes due to environmental influences and market requirements. Involvement in processes requires adapting process goals, flows, and tools to these changes.

- Clear competencies and responsibilities - In a matrix organizational structure, the notion of a process view is orthogonal to a traditional, functional organizational structure. Consequently, competencies and responsibilities should be clearly defined.

- Operationalized goals - It is necessary to ensure a more objective level of business, which is achieved by the operationalization of goals. Such goals make improvements more visible and reduce resistance to change.

- Goal Management - Process goals and employee goals should be linked.

- Remuneration system - Salary should be based on performance or according to some other criterion that encourages and supports the achievement of goals.

- Entrepreneurship - Processes are entities with independent responsibility for their results, in which employees can largely organize themselves according to the set goals in hotel industry.

The main task of these business process management solutions is to fully map and automate business processes in hotel entities. Introducing such principles into a hotel is a very demanding task that affects the overall business of the hotel. In order for business process management to be able to optimally plan the course of the business process, it is necessary to engage resources and continuously improve the management process.

As an example of an e-process from the world hotel industry, it is possible to mention the so-called "Call Shop" - a place for affordable internet calling in the hotel. This service offers benefits such as [2]:

- generating additional earnings that do not arise from the core business of the business entity,

- attracting guests due to affordable telephone services,

- possibility of integration with the hotel business system,

- possibility of integration into the info kiosk at frequent tourist locations,

- fast implementation in apartments and camps,

- Very fast return on investment (ROI) due to small investments and high profitability.

In addition to this system, Internet technology supports a number of other activities, such as interactive television in hotels. As an example of a company that offers its services to hotels on the Croatian market, we should point out the interactive television, which offers the following functions [3]:

- Live TV programs

- subscriber TV programs (PayTV)

- recording TV content (Time Shifting, Pause / Continue)

- Video On Demand (VOD)

- WWW access (surfing, e-mail, ...)

- communication between users (Instant Messaging)

- customizing the user interface

- monitoring and managing user rights. 


\section{Hotel Video-on-Demand Solution}

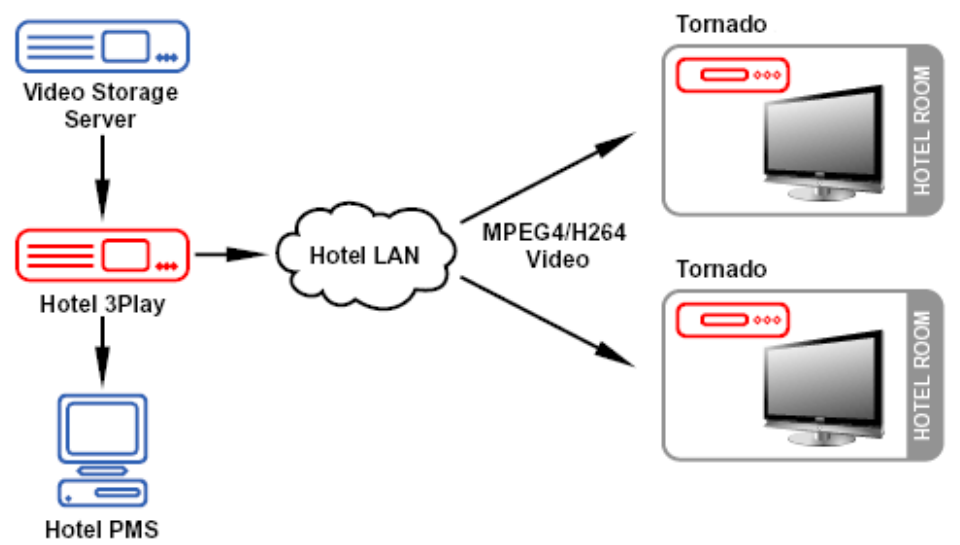

Fig. 1. Video on Demand process in hotel industry [9]

For example it is possible to mention Advantech's IPTV solutions which allow real-time distribution of TV channels, Video-on-Demand and other video content over broadband IP networks, such as the Internet. They enable providers to capture lucrative business opportunities by offering triple play services, delivered to their subscribers over broadband lines. Advantech's IPTV solutions fully support the delivery of bundled video, voice and data services over IP networks. A major benefit of our IPTV solutions is that they are fully integrated. (Fig.2.) [9]

These systems are applicable in the hotel industry and enable easy and fast ordering of services, satisfaction and loyalty of guests and complete technical adaptability of the solution with regard to the needs of hotel management.

\section{Customer Relationship Management as E-Process: Market Implications in Tourism}

Nowadays, companies are facing challenges that started to emerge in the 21 st century such as: globalisation, technology development, automation etc. In order to make the business successful in this highly competitive environment, managers should learn how to compete not only individually by their own companies but also in the entire supply chain they are involved. [10]

In order for hotels to achieve business success, these systems need to be planned as part of BPM. In more advanced hotel systems, it is necessary to integrate another marketing process CRM (Customer Relationship Management). Hotels must develop good relationships with potential and already current guests (clients). However, good relationships with clients do not arise spontaneously - they require the application of appropriate methods and business processes by which the hotel will establish control, or through which they will be able to manage these relationships. The set of such methods and business processes is called customer relationship management, which can be seen in Figure 2.

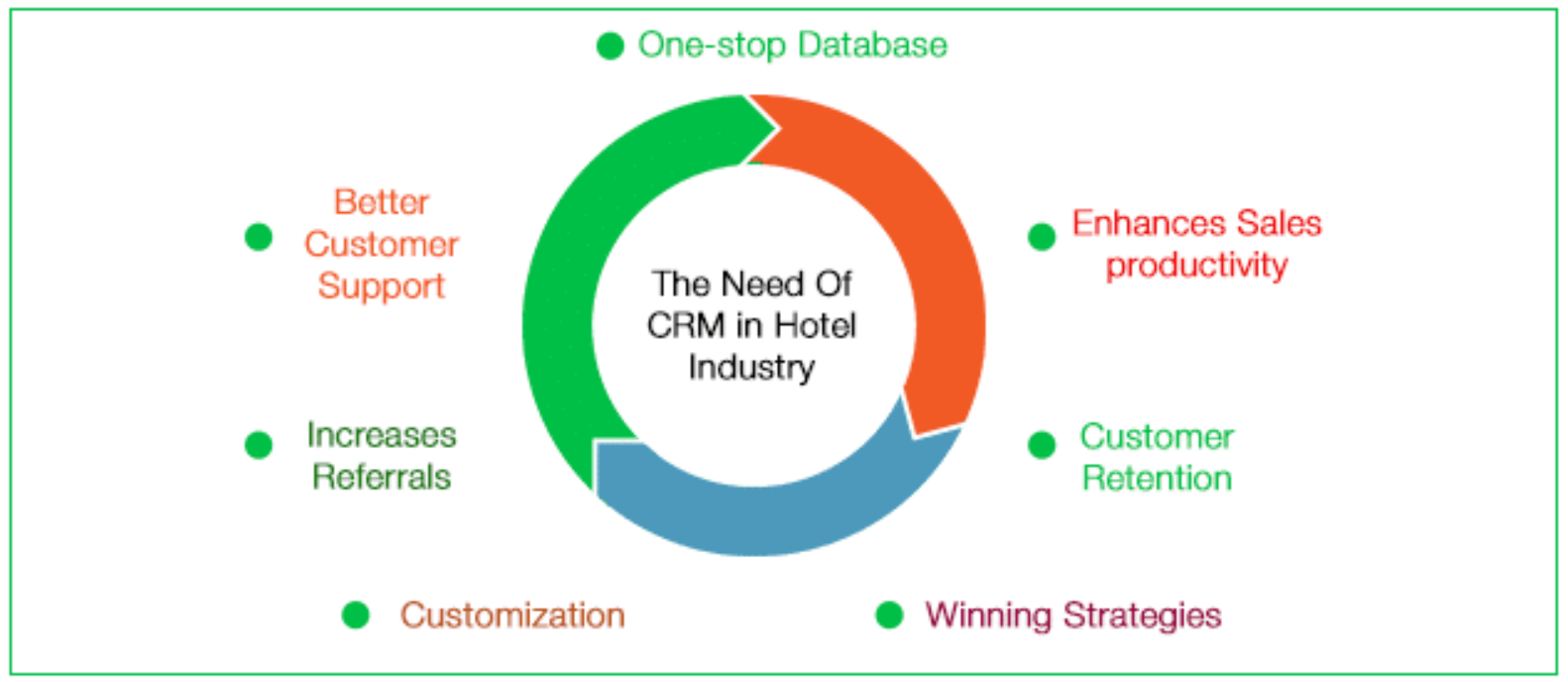

Fig. 2. Hypothetical Model of CRM [4] 
Accordingly, the preferred approach to CRM would be that customer relationship management (CRM) is a business strategy that affects the organization (hotel) as a whole: marketing, IT, services, logistics, finance, production and development, human resources, management, etc.

In today's globally competitive world, guests (clients) expect more, have more choices and are less loyal to hotel brands and tourist destinations. The only thing that is constant is change. Guests will continue to change their needs, demographics are changing, lifestyles are changing, as is consumer behavior. Hotels that will survive and grow will be those that understand change and not only understand it but create it. Many hotels work hard to attract new guests, but unfortunately often the relationship with the guest usually stops after the desired attraction.

Namely, it is quite difficult to simultaneously manage guests, processes, procedures, suppliers and technology and in all interactions with them, in a proactive way, in each phase of the guest life cycle in a way that guests would like by improving their experience with the hotel. The definition also shows the complexity of the customer relationship management strategy, ie all the elements that need to be under control. [5]

The essence of CRM is actually in cooperation with each guest in a way to achieve a win-win situation in which the hotel gives the guest a certain value in his daily life, and in return the guest reciprocates the hotel with loyalty. The development of the customer relationship management strategy itself is closely related to the development of technology that supports this strategy, and there is no need to explain further about the daily progress of technology. From a technological point of view, the progress and impact of technology on the customer relationship management strategy is clear, but there are still some problems in understanding the implementation of the customer relationship management strategy and the role of the technology itself. Often, in the implementation itself, too many expectations are placed on the technology. Therefore, it is understandable that there are a large number of definitions that focus on technology in defining a customer relationship management strategy.

In this case, CRM is defined as the automation of horizontally integrated business processes of hotels that include "front office customer contact points" (marketing, sales, services and support) through various communication channels. The above definition shows the positioning of CRM in the "IT sector". CRM is considered to be the integration of technological and business processes used to meet customer needs during any interaction that customers have with the hotel entity. In short, customer relationship management is the process by which a company makes good use of customer information to increase customer loyalty. In this regard, the primary goal of CRM is to build a long-term and profitable relationship with the selected segment of the tourism market in a way to be closer (achieve closeness) with these clients in each contact. Thus, it can be concluded that CRM is in fact a term from the information industry for methodology, software and usually Internet capacities that help hoteliers to manage customer relations in a more organized way. From this point of view, CRM is a strategic process of selecting guests that the hotel can profitably serve by creating and shaping the interaction between the hotel and the selected segment. [6]

Despite the fact that CRM brings lasting benefits to organizations, as a whole, some of them gain profits from implementing it more than others; CRM brings benefits to the organizations that generate a lot of information about customers. [7] [8]

\section{Conclusion}

The Internet provides support to a range of functions and processes in an economic operator in order to develop products and provide services to consumers. Then, it represents a powerful communication medium that can effectively connect the subjects of supply and demand in tourism. The research problem of this paper was to identify type and level of usage of e-processes in tourism marketing. Limitations of this researches were connected with some parts of data which can be used only for internal communication in tourism subjects, without publishing it in external publications. Consequently, new changed habits in the behaviour of consumers-tourists are emerging, which is primarily marked by the use of the Internet as an information, communication and transaction channel.

IT has become increasingly important in the tourism sector, due to the significant benefits it generates for all the agents involved, including hotels. In this regard, IT improve customer satisfaction, global market share, staff productivity and process standardization, and reduce operating costs. [11]

This category is, looking forward, at a wider global level in constant progression, so it will be included in future researches. Research of European and world practice in tourism and hospitality evidently shows greater competitiveness in business entities that base their business on modern Internet technology, especially Business Process Management (BPM) and Customer Relationship Management (CRM). These technical innovations will help in marketing management of tourism subjects to raise there revenues and to improve customer sastisfaction. 


\section{References}

[1] Lusk, S., Paley, S., Spanyi, A. (2005) The Evolution of Business Process Management as a Professional Discipline, Business Process Trends, 2005, p 5.

[2] Klepač, D. (2009) VoIP Direkt.NET, Conference ICT in Tourism, Proceedings

[3] Kolonić, L.(2009) : Interactive TV Bee smart, Conference ICT in Tourism, Proceedings

[4] https://cynoteck.com/blog-post/the-need-of-crm-in-hotel-industry/ (2020). Cynoteck portal, Accessed on: 2020-0913

[5] Temporal, P., Trott, M. (2001): Romancing the Customer: Maximizing Brand Value Through Powerful Relationship Management, John Wiley \& Sons, Singapore, p. 9

[6] Kevork, E.K., Vrechopoulos, A.P.(2009): CRM literature: conceptual and functional insights by keyword analysis, Marketing Intelligence \& Planning, Vol. 27., No. 1.,p. 48.

[7] Mohammed, A. A., \& Rashid, B. (2012). Customer Relationship Management (CRM) in Hotel Industry: A framework proposal on the relationship among CRM dimensions, Marketing Capabilities, and Hotel performance. International Review of Management and Marketing, Vol 2., No.4 p. 220.

[8] Shamsudin, M. F., Ishak, M. F., Hashim, M. A., Nabi, M. A., Yazid, M. F. M., \& Razak, A. A. (2019). Preliminary analysis on relationship of CRM functions implementation towards firm's business performance. Humanities \& Social Sciences Reviews, Vol. 7, No.1, p.113.

[9] http://advantech.com.sa/wp/?page_id=1031 (2020). Advantech portal, Accessed on: 2020-09-13

[10] Özdemir, A. İ., Çolak, A., \& Shmilli, J. (2019). Business process management in hotels: with a focus on delivering quality guest service. Quality \& Quantity, 53(5), 2305-2322.

[11] Melián-Alzola, L., Fernández-Monroy, M., \& Hidalgo-Peñate, M. (2020). Information technology capability and organisational agility: A study in the Canary Islands hotel industry. Tourism Management Perspectives, 33, 100606

[12] Biočina Lobaš, I., \& Račić, M. The importance of process reenngineering in the Hotel Industry. In Annals of DAAAM for 2002. \& Proceedings of the 13th International DAAAM Symposium, p. 35. 